\title{
The Cardiovascular Response to Lower Body Negative Pressure in Humans Depends on Seal Location
}

\author{
N. GOSWAMI ${ }^{1}$, E. GRASSER ${ }^{1}$, A. ROESSLER ${ }^{1}$, D. SCHNEDITZ ${ }^{1}$, \\ H. HINGHOFER-SZALKAY ${ }^{1,2}$ \\ ${ }^{1}$ Institute of Physiology, Center for Physiological Medicine, Medical University of Graz, ${ }^{2}$ Institute \\ of Adaptive and Spaceflight Physiology, Graz, Austria
}

Received October 18, 2007

Accepted March 27, 2008

On-line July 18, 2008

\section{Summary}

We tested whether seal location at iliac crest (IC) or upper abdomen (UA), before and during lower body negative pressure (LBNP), would affect thoracic electrical impedance, hepatic blood flow, and central cardiovascular responses to LBNP. After $30 \mathrm{~min}$ of supine rest, LBNP at $-40 \mathrm{mmHg}$ was applied for $15 \mathrm{~min}$, either at IC or UA, in 14 healthy males. Plasma density and indocyanine green concentrations assessed plasma volume changes and hepatic perfusion. With both sealing types, LBNP-induced effects remained unchanged for mean arterial pressure $(-3.0 \pm 1.1$ $\mathrm{mm} \mathrm{Hg})$, cardiac output $\left(-1.0 \quad \mid \mathrm{min}^{-1}\right)$, and plasma volume $(-11 \%)$. Heart rate was greater during UA $(80.6 \pm 3.3 \mathrm{bpm})$ than IC $(76.0 \pm 2.5 \mathrm{bpm})(\mathrm{p}<0.01)$ and thoracic impedance increased more using UA $(3.2 \pm 0.2 \Omega)$ than IC $(1.8 \pm 0.2 \Omega)(p<0.0001)$. Furthermore, during supine rest, UA was accompanied by lower thoracic impedance $(26.9 \pm 1.1$ vs $29.0 \pm 0.8 \Omega, p<0.001)$ and hepatic perfusion (1.6 vs $1.8 \mathrm{I} . \mathrm{min}^{-1}, \mathrm{p}<0.05$ ) compared to IC. The data suggest that the reduction in central blood volume in response to LBNP depends on location of the applied seal. The sealing in itself altered blood volume distribution and hepatic perfusion in supine resting humans. Finally, application of LBNP with the seal at the upper abdomen induced a markedly larger reduction in central blood volume and greater increases in heart rate than when the seal was located at the iliac crest.

\section{Key words}

Abdominal compression - Central blood volume - Orthostasis • Splanchnic blood flow $\bullet$ Thoracic electrical impedance

\section{Corresponding author}

N. Goswami, M.B.B.S., Institute of Physiology, Center for Physiological Medicine, Medical University of Graz, Harrachgasse 21/5, A-8010 Graz, Austria.

E-mail: nandu.goswami@meduni-graz.at

\section{Introduction}

In humans hypovolemic and orthostatic stress can be simulated by application of lower body negative pressure (LBNP), as this method leads to peripheral blood pooling and consequently to central hypovolemia (Gao et al. 2008). The splanchnic vascular bed representing the largest regional vascular conductance constitutes an important blood reserve (Escourrou et al. 1993 ) and is sensitive to baroreceptor stimulation. Thus, a low level of LBNP ( $\leq 20 \mathrm{~mm} \mathrm{Hg}$ ) is able to reduce splanchnic perfusion without changes in mean aortic pressure (Hirsch et al. 1989, Johnson et al. 1974). On the other hand, $50 \mathrm{~mm} \mathrm{Hg}$ of LBNP reduces splanchnic blood flow by more than $30 \%$ (Rowell et al. 1972) and reduces splanchnic vascular conductance by roughly the same percentage due to a rise in sympathetic activity (Brown et al. 1966).

In LBNP experiments the positioning of the seal separating the normo- and hypobaric zones of the body has varied widely: iliac crest, level of umbilicus, midabdomen, below the chest level, or may have not been reported. It is conceivable that varying sealing positions may affect the cardiovascular response. Using a seal around the iliac crest does not mechanically compress the bladder or the intestinal region and, therefore, does not compromise splanchnic blood flow (Brown et al. 1966). However, mesenteric hepatic blood flow, before and during LBNP, may be affected by increased abdominal pressure and the extent of compression of the splanchnic region caused by the location of the seal. An abdominal seal during LBNP compressing the abdominal region 
(Wasmund et al. 2003) could affect the circulation more than a seal positioned at the level of the iliac crest. Furthermore, external negative pressure applied to the abdomen would be expected to decrease central venous pressure, lung compliance, and airway pressure (Valenza et al. 2003).

In this study it was hypothesized that LBNP with upper abdomen (UA) sealing compresses the abdomen, provides suction on the splanchnic area, and creates a larger cardiovascular stress than does iliac crest (IC) sealing. It was also investigated whether the sealing position itself influenced central blood volume as assessed by thoracic electrical impedance, and/or cardiovascular responses to LBNP as assessed by heart rate and hepatic perfusion.

\section{Methods}

To avoid effects of confounding variables such as height, gender, or athletic training on cardiovascular responses during LBNP (Goswami et al. 2008) we carefully selected 14 healthy, male volunteers $(25 \pm 4$ years, $76 \pm 8 \mathrm{~kg}, 1.75 \pm 0.05 \mathrm{~m}$, and $1.72 \pm 0.15 \mathrm{~m}^{2}$ body surface area) of moderate physical fitness, free from cardiovascular, renal, and pulmonary diseases and not on any medication. Subjects abstained from the use of tobacco, caffeine, alcohol, and heavy exercise for at least $48 \mathrm{~h}$ preceding each investigation and the subjects served as their own controls. The study protocol was approved by the Graz Medical University Research Ethics Committee and written informed consent was obtained from each subject. Before the study, LBNP sham runs without blood sampling were carried out for familiarization (Laszlo et al. 1998).

Protocols were conducted between 9 and 12 a.m. to minimize circadian influences on hemodynamic variables (Gillen et al. 1994, Panza and Quyumi 1991) and were separated by two weeks. The subjects were fasting and emptied the bladder before each study. An antecubital vein was cannulated for blood sampling and administration of indocyanine green (ICG).

Experiments were carried out in a semi-dark and quiet room maintained at $24{ }^{\circ} \mathrm{C}$ and humidity at $55 \%$. A padded pair of tightly connected chains was used to stabilize and maintain an exact sealing position (Fig 1). The box was equipped with a footrest that was individually adjusted before LBNP was commenced. A pillow supported the head to avoid stimulation of the otolith organs which has been reported to increase muscle sympathetic nerve activity and calf vascular resistance (Hume and Ray 1999).

LBNP was applied with the seal at either the UA or IC (Fig. 1). The spine of the anterior superior iliac was the IC anatomical landmark; for the upper abdomen, the sealing level was at the lowest palpable rib in the midclavicular line, and therefore, included the splanchnic area in the region exposed to LBNP. Pressure within the box was lowered electronically by a pump within $10 \mathrm{~s}$ and monitored by an electronic gauge (Laszlo et al. 1998). LBNP (40 mmHg) lasted for $15 \mathrm{~min}$ since longer periods have been shown to affect LBNP tolerance (Greenleaf et al. 2000). During LBNP, subjects were instructed to avoid movements of the lower limbs and to breathe normally.

Baseline data were collected for $30 \mathrm{~min}$ in the supine position, with the seal in place, to allow for re-equilibration of gravity-related fluid shifts (Hagan et al. 1978). Each LBNP protocol involved sealing at either IC or UA with 14 days between studies in randomized order. The time course of the experimental protocol is shown in Figure 2.

\section{Blood volume and hepatic perfusion}

Indocyanine green (ICG, $25 \mathrm{mg}$ ) was injected 20 min before LBNP. Transcutaneous ICG concentrations were measured continuously by the DDG-2001K Dye Densitometer (Nihon Kohden, Japan) using a nose probe and the initial hemoglobin concentration was measured by standard techniques. Blood volume and hepatic blood flow were calculated from the amount of ICG injected and the measured ICG disappearance rate.

\section{Plasma volume shifts}

Plasma samples $(0.2 \mathrm{ml})$ were prepared from heparinized blood and measured within an hour. Plasma volume changes were determined from changes in plasma mass density (PD; $\mathrm{g} \mathrm{l}^{-1}$ at $37.0^{\circ} \mathrm{C}$ ) measured with a DMA 602 MW (Paar KG, Graz, Austria) (Hinghofer-Szalkay 1986). Changes in plasma volume (PV\%) were calculated from plasma density at baseline $\left(\mathrm{PD}_{\text {baseline }}\right)$ and at the end of LBNP (PD $\left.\mathrm{PBNP}_{\mathrm{LBN}}\right)$

$$
P V \%=\frac{P D_{\text {baseline }}-P D_{L B N P}}{P D_{L B N P}-1008} * 100
$$

where 1008 refers to the density of the filtered fluid (Hinghofer-Szalkay and Moser 1986). 


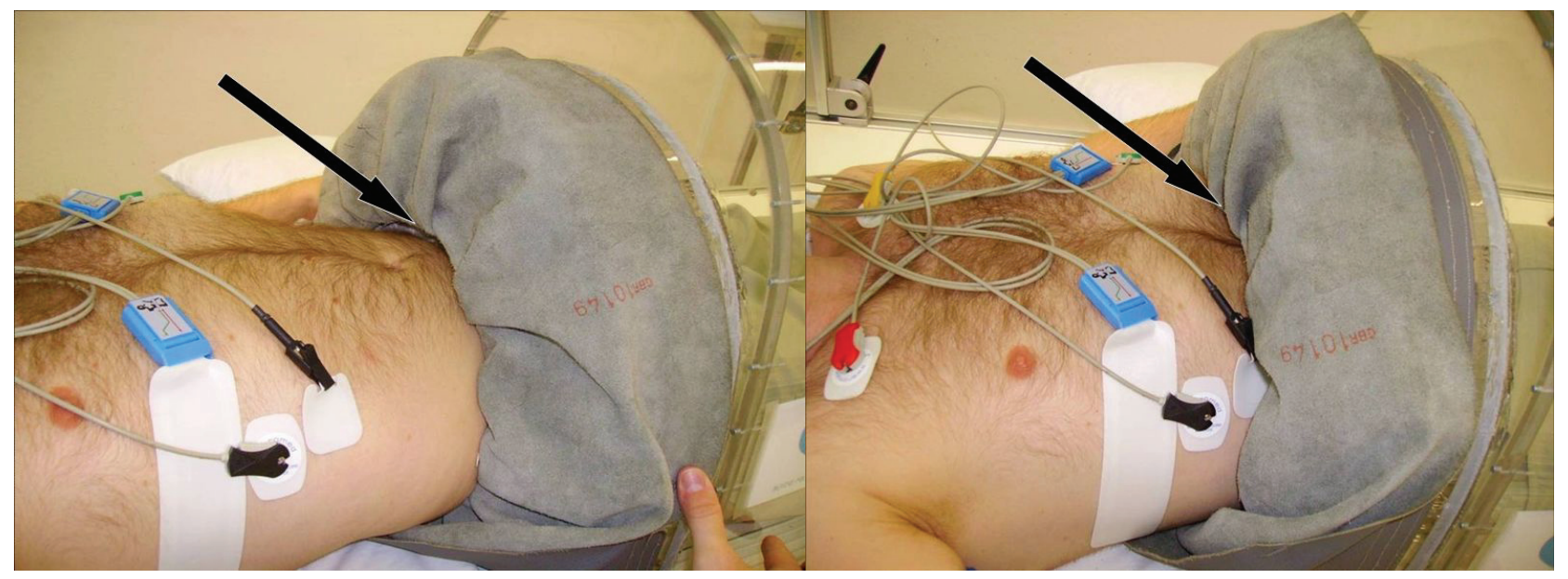

Fig. 1. Sealing at iliac crest (IC, left) and upper abdomen (UA, right panel) positions.

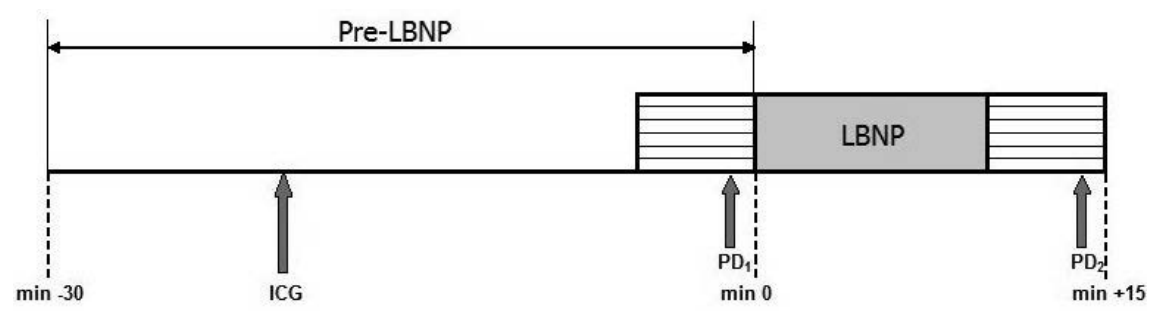

Fig. 2. Experimental protocol. ICG: Indocyanine green injection. Blood was collected for plasma density (PD) measurements. Hemodynamic data were used from 5 min immediately preceding LBNP and from LBNP minute 10 to 15 (hatched areas).

\section{Thoracic electrical impedance}

For an estimate of changes in central blood volume, thoracic electrical impedance was monitored (Task Force Monitor, CNSystems, Graz, Austria). Surface electrodes were placed at the neck and at the midclavicular line at the xiphoid process level (Fortin et al. 2006).

\section{Hemodynamics}

Blood pressure and heart rate were measured using a finger cuff (Finometer; Finapres Medical Systems, Arnhem, The Netherlands) and calibrated to standard arm cuff measurements. This system also provides an estimate of cardiac stroke volume and is becoming increasingly used in physiological and clinical research (Schneditz et al. 2008).

\section{Data analysis}

Data are expressed as means \pm S.E.M. Hemodynamic variables were averaged over $5 \mathrm{~min}$ windows preceding the start and end of LBNP, respectively. Hypothesis testing was carried out using two-way ANOVA with main effects of LBNP and sealing position. A probability $\mathrm{p}<0.05$ rejected the nullhypothesis.
Table 1. Effect of sealing position on hepatic perfusion and thoracic impedance.

\begin{tabular}{cccc}
\hline \multicolumn{4}{c}{ Rest (Pre-LBNP) } \\
\hline \\
$\begin{array}{c}\text { Blood } \\
\text { volume } \\
(\mathbf{I})\end{array}$ & $\begin{array}{c}\text { Liver } \\
\text { perfusion } \\
\left(\mathbf{l} \mathbf{~ m i n}^{-1}\right)\end{array}$ & $\begin{array}{c}\text { Thoracic } \\
\text { impedance } \\
(\mathbf{\Omega})\end{array}$ \\
\hline$I C$ & $5.9 \pm 0.3$ & $1.8 \pm 0.1$ & $29.0 \pm 0.8$ \\
$U A$ & $5.9 \pm 0.2$ & $1.6 \pm 0.1^{*}$ & $26.9 \pm 1.1^{*}$ \\
\hline
\end{tabular}

* refers to $\mathrm{p}<0.05$ between sealing positions

\section{Results}

Although blood volume at rest was not different between the two applied sealing positions (5.9 \pm 0.31 ), resting values of liver perfusion and thoracic electrical impedance were different $(\mathrm{p}<0.05)$ (Table 1). Resting UA was characterized by lower thoracic impedance $(26.9 \pm 1.1$ vs. $29.0 \pm 0.8 \Omega, \mathrm{p}<0.001)$ and hepatic perfusion (1.6 vs. $\left.1.81 \mathrm{~min}^{-1}, \mathrm{p}<0.05\right)$ compared to IC.

During LBNP, heart rate was greater during UA $(80.6 \pm 3.3 \mathrm{bpm})$ than IC $(76.0 \pm 2.5 \mathrm{bpm})(\mathrm{p}<0.01)$ and thoracic impedance increased more during UA $(3.2 \pm 0.2 \Omega)$ than IC $(1.8 \pm 0.2 \Omega)$ application $(\mathrm{p}<0.0001)$. Stroke volume 
was reduced by $30 \%$ in UA and $25 \%$ in IC, but the difference did not reach significance $(p=0.1)$. With both sealings, LBNP-induced effects remained unchanged for mean arterial pressure $(-3.0 \pm 1.1 \mathrm{mmHg})$, cardiac output $\left(-1.01 . \mathrm{min}^{-1}\right)$ and plasma volume changes $(-11 \%)$.

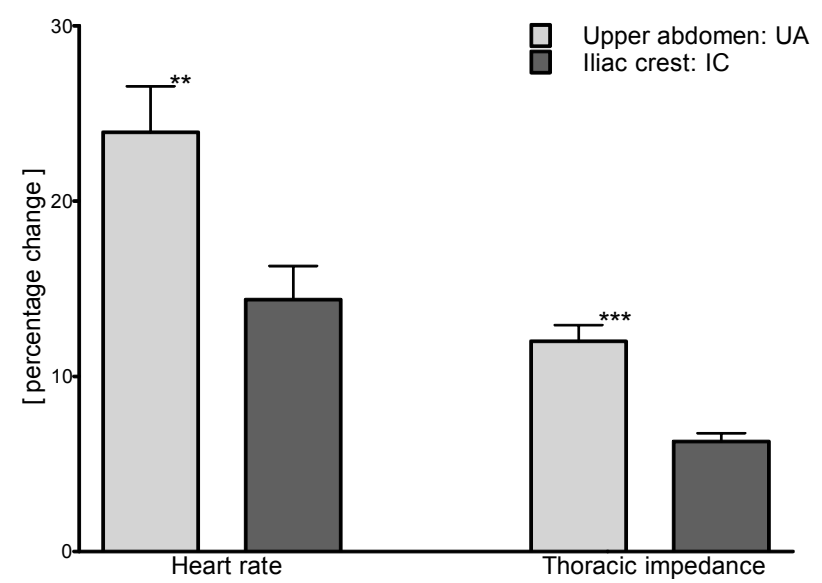

Fig 3. Heart rate and thoracic impedance changes during LBNP application. Values are relative to pre-LBNP values.

\section{Discussion}

This study found that the position of the seal used for lower body negative pressure had important effects on cardiovascular variables, and that some differences were present before the application of LBNP. More specifically, central blood volume, as indicated by increased thoracic electrical impedance, was reduced at rest when the seal was placed in the UA position with consequences for heart rate and splanchnic blood flow. Furthermore, when LBNP was applied there was a more pronounced increase in heart rate when the LBNP included the abdominal region.

Baseline thoracic impedance (TI) is inversely related to thoracic fluid volume (Pomerant et al. 1970) and central blood volume (Cai et al. 2000, Ebert et al. 1986). The pre-LBNP differences which we observed can be interpreted as indications for fluid displacement with the simple placement of the UA seal that increased central blood volume. Tanaka et al. (1997) experimented with inflatable abdominal cuffs and observed a blood shift from the splanchnic to the thoracic region. Compression of the abdomen and limbs has also been shown to increase the effective circulating blood volume (Denq et al. 1997, Uemura et al. 1999). It is also plausible that stimulation of low threshold skin afferents and mechanical compression of abdominal adipose tissue may have modulated sympathetic neural outflow, but it is more likely that the differences seen between the sealing positions were due to regional fluid shifts.

During LBNP, higher thoracic impedance and a larger increase in heart rate were observed with UA. This suggests a larger reduction in central blood volume (not only relative) and an increased sequestration of blood into lower body regions when the seal was located in UA position. This is in support of concomitant femoral vein distension and caval vein narrowing during compression of the abdomen (Smit et al. 2004). The larger heart rate response to LBNP with UA can be explained by a greater reduction of cardiac preload, as indicated by the different degrees of thoracic impedance responses during LBNP. Cardiopulmonary receptors mediate LBNP effects (Furlan et al. 2001) with resulting tachycardia, reduced forearm as well as splanchnic blood flows. Pulse pressure changes, however, did not differ between UA and IC (Table 2). As the diastolic and systolic pressures were similar in both groups, we believe that the different heart rate response was driven by the different magnitude of cardiopulmonary receptor unloading (greater in UA than in IC).

The stability of arterial blood pressure was expected (Bevegard et al. 1977, Brown et al. 1966, Laszlo et al. 1998) at this level of LBNP as arterial blood pressure is maintained by both peripheral vascular resistance and heart rate adjustments (Kitano et al. 2005).

The LBNP-induced reduction in stroke volume was also expected (Ahmad et al. 1977, Laszlo et al. 1998, Stevens and Lamb 1965), but the effect was larger with UA than IC (see above). If attachment of the seal at UA itself caused an increased cardiac preload, it is conceivable that the elevated starting point of LBNP provided a larger volume reserve during the LBNP challenge, possibly allowing for a larger drop in stroke volume. This is in agreement with a larger stroke volume decrease we observed with UA sealing.

We observed a $15 \%$ decrease in cardiac output during LBNP, similar to that found by others (Berk et al. 1990, Stevens and Lamb 1965). Plasma volume loss with orthostatic stress occurs primarily in the lower limbs (Wolthius et al. 1970) and as both sealing locations had an equal effect on plasma density, it is conceivable that plasma volume loss was the same in UA and IC.

We used ICG clearance to assess hepatic flow before LBNP (Cherrick et al. 1960, Valenza et al. 2003) because application of the seal at the UA position might influence hepatic perfusion. At rest, before LBNP, hepatic perfusion was reduced by $11 \%$ with UA compared to IC. 
Table 2. Hemodynamic and plasma density data. Heart rate (HR) and thoracic impedance (TI) were significantly altered from 5 min pre-LBNP to the last $5 \mathrm{~min}$ of LBNP. Differences of normalized changes between UA and IC are given in Figure 3. LBNP effects on cardiac output, peripheral resistance, pulse pressure and plasma density were all significant, but there was no difference between IC and UA. Arterial pressures did not change with LBNP, except for systolic blood pressure, which decreased by $8.4 \%$ in both conditions.

\begin{tabular}{|c|c|c|c|c|}
\hline & \multicolumn{2}{|c|}{ Pre LBNP } & \multicolumn{2}{|c|}{ During LBNP } \\
\hline & IC & $\mathbf{U A}$ & IC & UA \\
\hline$H R(b p m)$ & $66.7 \pm 2.3$ & $66.8 \pm 3.2$ & $76.0 \pm 2.5$ & $80.6 \pm 3.3^{*}$ \\
\hline$S V(m l)$ & $97.1 \pm 5.8$ & $99.1 \pm 4.8$ & $72.4 \pm 4.8$ & $70.2 \pm 5.0$ \\
\hline$T I(\Omega)$ & $29.0 \pm 0.8$ & $26.9 \pm 1.1 *$ & $30.8 \pm 0.9$ & $30.1 \pm 1.1$ \\
\hline$M A P(m m ~ H g)$ & $97.4 \pm 1.4$ & $96.4 \pm 2.1$ & $94.2 \pm 2.1$ & $93.7 \pm 2.0$ \\
\hline$D B P(m m ~ H g)$ & $78.7 \pm 1.9$ & $77.7 \pm 1.9$ & $79.6 \pm 2.1$ & $78.9 \pm 2.1$ \\
\hline$S B P(m m ~ H g)$ & $130.8 \pm 1.4$ & $131.3 \pm 2.3$ & $120.2 \pm 2.7$ & $120.3 \pm 2.0$ \\
\hline$P P(m m H g)$ & $52.0 \pm 2.0$ & $53.8 \pm 1.2$ & $40.5 \pm 2.1$ & $41.4 \pm 1.5$ \\
\hline$T P R\left(m m H g s m l^{-1}\right)$ & $0.95 \pm 0.07$ & $0.91 \pm 0.04$ & $1.11 \pm 0.08$ & $1.05 \pm 0.05$ \\
\hline$C O\left(l \min ^{-1}\right)$ & $6.5 \pm 0.4$ & $6.5 \pm 0.3$ & $5.5 \pm 0.4$ & $5.5 \pm 0.3$ \\
\hline$P D\left(g l-1,37.0^{\circ} \mathrm{C}\right)$ & $1019.21 \pm 0.13$ & $1019.22 \pm 0.17$ & $1020.44 \pm 0.13$ & $1020.64 \pm 0.23$ \\
\hline
\end{tabular}

* refers to $\mathrm{p}<0.05$ between sealing positions. MAP - mean arterial pressure; DBP - diastolic pressure; SBP - systolic pressure; PP pulse pressure; TPR - total peripheral resistance; CO - cardiac output; PD - plasma density.

As most of the liver and spleen are protected by the ribcage, and may not have been directly compressed by the seal (perhaps except of the lower right lobe of the liver), it is conceivable that the pressure generated by the seal below the ribcage was indirectly transmitted through the abdominal space to the liver thus affecting hepatic blood flow. However, the effect need not be direct. The likely reduction in central blood volume in itself increases sympathetic activity and reduces splanchnic blood flow (Brooksby and Donald 1971).

Thoracic impedance is affected by ventilation (Dowell et al. 1969). Application of the seal at UA could cause differences in regional lung volumes (Frerichs et al. 2005) as well as in the depth of breathing (Furlan et al. 2001). In our study, hemodynamic data were obtained with the Finometer system. Finometer measurements correlate well with intra-arterial measurements of blood pressure (Imholz et al. 1990) and have been validated in subjects undergoing stress situations (Parati et al. 1989). Hemodynamic monitoring with the Finometer system has its own limitations since it may be affected by bias and drift and, therefore, relative changes in blood pressure were analyzed rather than absolute values (Lee et al. 2004). To avoid drift, we calibrated to absolute values from conventional cuff measurements on the contralateral upper arm every $15 \mathrm{~min}$.

There are some limitations in this study. First, it cannot be ruled out that sympathetic neural activity was directly modulated by applying suction onto the abdominal area, in addition to cardiovascular reflex effects. It appears, however, that most likely the effects observed in this study resulted from the corresponding blood volume shifts (Cai et al. 2000, Ebert et al. 1986, Pomerant et al. 1970). It is also conceivable that the pressure applied at the sealing was not always identical at each LBNP even in the same subject and this could have affected the results. Second, even if the effects of the seal were most likely mediated by changes in intra-abdominal pressures, intra-abdominal pressure was not measured in this study. While intravesical pressure may be a good surrogate for intra-abdominal pressure in the clinical setting, in this study one would have to measure small pressure changes in the upper abdomen which are not accessible by non-invasive and indirect means. Furthermore, thoracic impedance and ICG elimination are indirect measures, but they indicate thoracic fluid content, splanchnic flow and liver blood flow (Rowell et al. 1972) with sufficient reliability, and have been repeatedly used for this purpose in previous studies (Brown et al. 1966, Cai et al. 2000, Hinghofer-Szalkay et al. 2008).

To summarize, LBNP sealing positions influenced hemodynamic responses to LBNP, and sealing attachment had an effect of its own. Liver blood flow and thoracic impedance were different between the two sealing locations pre-LBNP, an effect largely attributable to pressure exerted by the seal at these sites. During LBNP, a larger increase in heart rate was observed with UA, as opposed to IC, placement, secondary to a greater 
reduction in cardiac preload, as indicated by different degrees in thoracic impedance responses during LBNP.

\section{Conflict of Interest}

There is no conflict of interest.

\section{Acknowledgements}

We appreciate the useful comments and excellent contributions of Prof. Neils Secher, Rigshospitalet, Copenhagen, Denmark, during the preparation of the manuscript. We wish to thank Andreas Jantscher and Isolde Bachler for their excellent technical support during the experiments. The funds for the Finometer and the DDG-2001K Dye Densitometer were provided by the infrastructure grant UGP4 of the Austrian Ministry of Science, Education, and Art.

\section{References}

AHMAD M, BLOMQVIST CG, MULLINS CB, WILLERSON JT: Left ventricular function during lower body negative pressure. Aviat Space Environ Med 48: 512-515, 1977.

BERK MR, XIE GY, KWAN OL: Reduction of left ventricular preload by lower body negative pressure alters Doppler transmitral filling patterns. J Am Coll Cardiol 16: 1387-1392, 1990.

BEVEGARD S, CASTENFORS J, LINDBLAD LE, TRANESJO J: Blood pressure and heart rate regulating capacity of the carotid sinus during changes in blood volume distribution in man. Acta Physiol Scand 99: 300-312, 1977.

BROOKSBY GA, DONALD DE: Dynamic changes in splanchnic blood flow and blood volume in dogs during activation of sympathetic nerves. Circ Res 29: 227-231, 1971.

BROWN E, GOEI JS, GREENFIELD AD, PLASSARAS GC: Circulatory responses to simulated gravitational shifts of blood in man induced by exposure of the body below the iliac crests to sub-atmospheric pressure. $J$ Physiol Lond 183: 607-627, 1966.

CAI Y, HOLM S, JENSTRUP M: Electrical admittance for filling of the heart during lower body negative pressure in humans. J Appl Physiol 89: 1569-1576, 2000.

CHERRICK GR, STEIN SW, LEEVY CM, DAVIDSON CS: Indocyanine green - observations on its physical properties, plasma decay, and hepatic extraction. J Clin Invest 39: 592-600, 1960.

DENQ JC, OPFERGEHRKING TL, GIULIANI M, FELTEN J, CONVERTINO VA, LOW PA: Efficacy of compression of different capacitance beds in the amelioration of orthostatic hypotension. Clin Auton Res 7: 321-326, 1997.

DOWELL AR, SCHAAL SF, SPIELVOGEL R, POHL SA: Effect of lower body negative pressure upon pulmonary ventilation and perfusion as measured using xenon-133. Aerosp Med 40: 651-657, 1969.

EBERT TJ, SMITH JJ, BARNEY JA, MERRILL DC, SMITH GK: The use of thoracic impedance for determining thoracic blood-volume changes in man. Aviat Space Environ Med 57: 49-53, 1986.

ESCOURROU P, RAFFESTIN B, PAPELIER Y, PUSSARD E, ROWELL LB: Cardiopulmonary and carotid baroreflex control of splanchnic and forearm circulations. Am J Physiol 264: H777-H782, 1993.

FRERICHS I, BODENSTEIN M, DUDYKEVYCH T, HINZ J, HAHN G, HELLIGE G: Effect of lower body negative pressure and gravity on regional lung ventilation determined by EIT. Physiol Meas 26: S27-S37, 2005.

FORTIN J, HABENBACHER W, HELLER A: Non-invasive beat-to-beat cardiac output monitoring by an improved method of transthoracic bioimpedance measurement. Comput Biol Med 36: 1185-1203, 2006.

FURLAN R, JACOB G, PALAZZOLO L: Sequential modulation of cardiac autonomic control induced by cardiopulmonary and arterial baroreflex mechanisms. Circulation 104: 2932-2937, 2001.

GAO Y, GOSWAMI N, GRASSER E, ROESSLER A, STOEGER E, HINGHOFER-SZALKAY H: Radix Astragali and orthostatic response: a double masked crossover study. Aviat Space Environ Med. 79: 94-98, 2008.

GILLEN CM, NISHIYASU T, LANGHANS G, WESEMAN C, MACK GW, NADEL ER: Cardiovascular and renal function during exercise-induced blood volume expansion in men. J Appl Physiol 76: 2602-2610, 1994.

GOSWAMI N, LOEPPKY J, HINGHOFER-SZALKAY H: LBNP: Past protocols and technical considerations for experimental design. Aviat Space Environ Med 79: 1-13, 2008. 
GREENLEAF JE, PETERSEN TW, GABRIELSEN A: Low LBNP tolerance in men is associated with attenuated activation of the renin-angiotensin system. Am J Physiol 279: R822-R829, 2000.

HAGAN RD, DIAZ FJ, HORVATH SM: Plasma volume changes with movement to supine and standing positions. J Appl Physiol 45: 414-418, 1978.

HINGHOFER-SZALKAY H: Method of high precision microsample blood and plasma mass densitometry. $J$ Appl Physiol 60: 1082-1088, 1986.

HINGHOFER-SZALKAY H, MOSER M: Fluid and protein shifts after postural changes in humans. Am J Physiol 250: H68-H75, 1986.

HINGHOFER-SZALKAY HG, GOSWAMI N, RÖSSLER A, GRASSER E, SCHNEDITZ D: Reactive hyperemia in the human liver. Am J Physiol Gastrointest Liver Physiol 295: G332-G337, 2008.

HIRSCH AT, LEVENSON DJ, CUTLER SS, DZAU VJ, CREAGER MA: Regional vascular responses to prolonged lower body negative pressure in normal subjects. Am J Physiol 257: H219-H225, 1989.

HUME KM, RAY CA: Effect of head-down neck extension on muscle sympathetic nerve activity: implication for the vestibulosympathetic reflex. FASEB J 13: A127-A127, 1999.

IMHOLZ BPM, SETTELS JJ, VANDERMEIRACKER AH, WESSELING KH, WIELING W: Non-invasive continuous finger blood-pressure measurement during orthostatic stress compared to intra-arterial pressure. Cardiovasc Res 24: 214-221, 1990.

JOHNSON JM, ROWELL LB, NIEDERBE M, EISMAN MM: Human splanchnic and forearm vasoconstrictor responses to reductions of right atrial and aortic pressures. Circ Res 34: 515-524, 1974.

KITANO A, SHOEMAKER JK, ICHINOSE M, WADA H, NISHIYASU T: Comparison of cardiovascular responses between lower body negative pressure and head-up tilt. $J$ Appl Physiol 98: 2081-2086, 2005.

LASZLO Z, ROSSLER A, HINGHOFER-SZALKAY HG: Cardiovascular changes during and after different LBNP levels in men. Aviat Space Environ Med 69: 32-39, 1998.

LEE K, BUCHANAN DB, FLATAU AB, FRANKE WD: Reproducibility of the heart rate variability responses to graded lower body negative pressure. Eur J Appl Physiol 92: 106-113, 2004.

PANZA JA, QUYYUMI AA: Circadian variation in vascular tone and its relation to alpha-sympathetic vasoconstrictor activity. N Engl J Med 325: 986-990, 1991.

PARATI G, CASADEI R, GROPPELLI A, DIRIENZO M, MANCIA G: Comparison of finger and intra-arterial bloodpressure monitoring at rest and during laboratory testing. Hypertension 13: 647-655, 1989.

POMERANT M, DELGADO F, EISEMAN B: Clinical evaluation of transthoracic electrical impedance as a guide to intrathoracic fluid volumes. Ann Surg 171: 686-691, 1970.

ROWELL LB, WYSS C, BLACKMON JR, DETRY JMR: Importance of splanchnic vascular bed in human bloodpressure regulation. J Appl Physiol 32: 213-219, 1972.

SCHNEDITZ D, BACHLER I, STADLBAUER V, STAUBER RE: Albumin infusion fails to restore circulatory function following paracentesis of tense ascites as assessed by beat-to-beat haemodynamic measurements. Int J Clin Practice 62: 1851-1857, 2008.

SMIT AAJ, WIELING W, FUJIMURA J, DENQ JC: Use of lower abdominal compression to combat orthostatic hypotension in patients with autonomic dysfunction. Clin Auton Res 14: 167-175, 2004.

STEVENS PM, LAMB LE: Effects of lower body negative pressure on the cardiovascular system. Am J Cardiol 16: 506-515, 1965.

TANAKA H, YAMAGUCHI H, TAMAI H: Treatment of orthostatic intolerance with inflatable abdominal band. Lancet 349: 175-176, 1997.

UEMURA M, MATSUMOTO M, TSUJII SA: Effect of body compression on parameters related to ascites formation: therapeutic trial in cirrhotic patient. J Gastroenterol 34: 75-82, 1999.

VALENZA F, BOTTINO N. CANAVESI K: Intra-abdominal pressure may be decreased non-invasively by continuous negative extra-abdominal pressure (NEXAP). Intensive Care Med 29: 2063-2067, 2003.

WASMUND SL, SMITH ML, TAKATA TS, JOGLAR JA, LI JM, KOWAL RC: Sympathoexcitation is attenuated during low level lower body negative pressure in subjects who develop pre-syncope. Clin Auton Res 13: 208$213,2003$. 
WOLTHUIS RA, HOFFLER GW, JOHNSON RL: Lower body negative pressure as an assay technique for orthostatic tolerance. 3. A comparison of the individual response to incremental leg negative pressure vs. incremental lower body negative pressure. Aerosp Med 41: 1354-1357, 1970. 